\title{
Evaluation of Cephalic Index in children from the Madheshi community in Sarlahi district, Nepal
}

\author{
Surendra Kumar Sah ${ }^{1}$, Man Kumar Tamang, ${ }^{2,3}$ Om Prakash Yadav, ${ }^{4}$ Amit Kumar Shah ${ }^{5}$ \\ ${ }^{1}$ Assistant Professor, Department of Anatomy, Nobel Medical College Teaching Hospital, Biratnagar, Nepal, ${ }^{2}$ PhD \\ Scholar, Queensland Brain Institute, The University of Queensland, Brisbane, Australia, ${ }^{3}$ Research Assistant, Center \\ for Research Policy and Implementation, Biratnagar, Nepal, ${ }^{4} \mathrm{Health}$ Assistant, Ministry of Social Development, \\ Province no.1, Biratnagar, ${ }^{5}$ Medical Officer, Dadeldhura Hospital, Dadeldhura, Nepal
}

Background: Cephalic index is one of the important craniofacial parameters which is commonly used for investigating the length and breadth of the head. Cephalic Index (Cl) is defined as the ratio between maximum breadth of the head and the maximum length of the head multiplied by 100 . Body mass index (BMI) is a nutritional marker of the body derived from the measurement of height (in $\mathrm{m}^{2}$ ) and weight (in $\mathrm{kg}$ ). Aims and Objective: To analyse the effect of $\mathrm{BMI}$ on the $\mathrm{Cl}$. Materials and Methods: This study was a cross-sectional study conducted from April 2021 to June 2021 with sample size of 200 children of age groups 5-8 years from Ramnagar Gaupalika of Sarlahi, Province 2, of Nepal. We measured the cephalic index of the children and asked a set of structured questionnaire to the guardian or parent of the children. Height and weight of the children were also measured and BMI was determined. Data analysis was completed using SPSS version 16. Results: The mean age of the participants was 6.56 years, BMI of 18.09 and cephalic index $(\mathrm{Cl})$ of 81.82 . The mean $\mathrm{Cl}$ in males and females were 82.05 and 81.59 respectively. Our results show significant association between $\mathrm{BMI}$ category and $\mathrm{Cl}$ category (chisquare test, $\mathrm{p}$-value $=0.000$ ), mode of delivery and $\mathrm{BMI}$ category (chisquare test, $\mathrm{p}=0.042$ ) and significant negative correlation between $\mathrm{BMI}$ and $\mathrm{Cl}$ (Pearson's $\mathrm{R}=-0.591, \mathrm{p}=0.037$ ). Conclusion: The most common pattern of $\mathrm{Cl}$ was hyperbrachycephalic in the children of low $\mathrm{BMI}$ whereas the pattern of $\mathrm{Cl}$ in case of the normal BMI was the mesocephalic type. It also confirmed that the sexual dimorphism exists in both the low BMI and the normal BMI.

Key words: Cephalic Index; BMI; Madheshis community; Nepal
http://nepjol.info/index.php/AJMS DOI: 10.3126/ajms.v12i10.37924 E-ISSN: 2091-0576 P-ISSN: 2467-9100

Copyright (c) 2021 Asian Journal of Medical Sciences

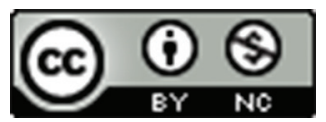

This work is licensed under a Creative Commons Attribution-NonCommercial 4.0 International License.

\section{INTRODUCTION}

Cephalic index is one of the important craniofacial parameters which is commonly used for investigating the length and breadth of the head. ${ }^{1}$ Cephalic Index (CI) is defined as the ratio between maximum breadth of the head and the maximum length of the head multiplied by 100. Maximum breadth is measured by considering the distance between the two parietal eminence of the skull. The maximum length of the head is measured by taking in consideration the distance between the glabella and the inion on the external occipital protuberance. ${ }^{2}$ Craniofacial measurements are essential for determining various shapes of head and face. Craniometry is an important branch of anthropometry through which cranial dimensions can be measured. Skull index information is one of the important criteria for studying and comparing the skulls of people with various essential differences in nutrition, race, geography, and ethnicity. ${ }^{3}$

Body mass index (BMI) is derived from the mass (weight) and height of a person. BMI is defined as the body mass divided by the square of the body height, expressed in $\mathrm{kg} / \mathrm{m}^{2}$. BMI is a convenient rule of thumb which is used 
to broadly categorize an individual under different category of underweight, normal weight, overweight, or obese based on the tissue mass (i.e, muscles, fats, and bones) and height. The most commonly accepted BMI reference ranges are underweight $\left(<18.5 \mathrm{~kg} / \mathrm{m}^{2}\right)$, normal weight $(18.5-25)$, overweight $(25-30)$, and obese $(>30){ }^{4}$

$\mathrm{BMI}$ is also utilized to determine the quantitative factor that may cause serious impairment of growth including growth and development of craniofacial parameters. ${ }^{5}$ The pathophysiology of bone disease across all ages is greatly influenced by the genetic, environmental, and the hormonal factors. The composition of the body, especially in individuals at extremes of the weight spectrum, exerts a significant effect on growth of bone, geometry, and subsequent fracture risk. ${ }^{6}$ As the children grow, the amount of fats in the body changes and naturally their BMI as well. Some diseases such as infection, chronic and genetic disease may be influencing their process of growth and development in children. BMI may mark the growth and development and health development has been well documented to show that the two are closely related to the child's physical as well as mental condition. ${ }^{7}$

Based on the above information it is reasonable to correlate the growth of skull (i.e.CI) in relation to the BMI of the children. This association can demonstrate influence of nutritional status of the children on the growth of skull and intellectual development of children.

\section{MATERIALS AND METHODS}

\section{Study setting}

This was a cross-sectional study conducted from April 2021 to June 2021 with a sample size of 200 children $(N=200)$ of age groups 5-8 years from Ramnagar Gaupalika of Sarlahi district Province 2 of Nepal. The following are the criteria to include and exclude participants.

\section{Inclusion criteria}

Apparently healthy children.

\section{Exclusion criteria}

Children with confirmed Craniofacial deformity.

\section{Data collection method}

We used a structured questionnaire to record the age, mode of delivery, breast feeding status, major staple foods and alcohol consumption by mother during pregnancy. Then a standard digital weighing machine was used to measure weight (in $\mathrm{kg}$ ) and a tape to measure height (in $\mathrm{cm}$ ) of the child. BMI was calculated from the height and weight of the child. We used the following criteria to categorize BMI:
Underweight $\left(<18.5 \mathrm{~kg} / \mathrm{m}^{2}\right)$, Normal weight (18.5 - 25), Overweight (25 - 30), and Obese $(>30)^{4}$.

In order to measure the Cephalic Index (CI), the subjects were asked to sit on a chair in Anatomical position of head considering the Frankfurt's line. The measurement of CI was done by using the digital Vernier Caliper. The anteroposterior diameter of the head was measured from the Glabella anteriorly to the Inion posteriorly. The transverse diameter was measured by taking the two parietal eminence of both the sides of head. Then the CI was calculated by using the formula,

Cephalic Index $(\mathrm{CI})=$ Transverse diameter/Anteroposterior diameterX100.

Various types of Cephalic Index with reference are Dolicocephalic (<74.9), Mesocephalic (75-79.9), Brachycephalic (80-84.9) and Hyperbrachycephalic (85-89.9).

\section{Ethical approval and informed consent}

Ethical approval was obtained from the Institutional Review Committee of Nobel Medical College, Biratnagar. An informed consent was obtained from the guardians/ parents of all the children after providing them brief information about the study.

\section{Statistical analysis}

Data was entered into MS Excel and raw data were cleaned. The cleaned data was entered into SPSS version 16 to generate descriptive statistics. Association between the independent variables and cephalic index was assessed using chi-square test. Correlation analysis was done to assess relationship between BMI and CI.

\section{RESULTS}

A total of 200 children $(\mathrm{N}=200)$ aged $5-8$ years of old were enrolled in the study. The mean age of the participants was 6.56 years, BMI of 18.09 and cephalic index (CI) of 81.82. The mean CI in males and females were 82.05 and 81.59 respectively, but they were not significantly different $(\mathrm{p}$-value $=0.548)$ as represented in Table 1 . Of total, $53 \%$ of the children were mesocephalic (the classification of the children based on CI is given in Figure 1).

Our results show significant association between BMI category and CI category (chi-square test, $\mathrm{p}$-value $=0.000$ ), mode of delivery and BMI category (chi-square test, $\mathrm{p}=0.042)$ and significant negative correlation between BMI and CI (Pearson's R=-0.591, $\mathrm{p}=0.037$ ) (as shown in Figure 2). However, when the participants were grouped 
by their BMI (either low or normal BMI), the males and females had significantly different CI (Table 2).

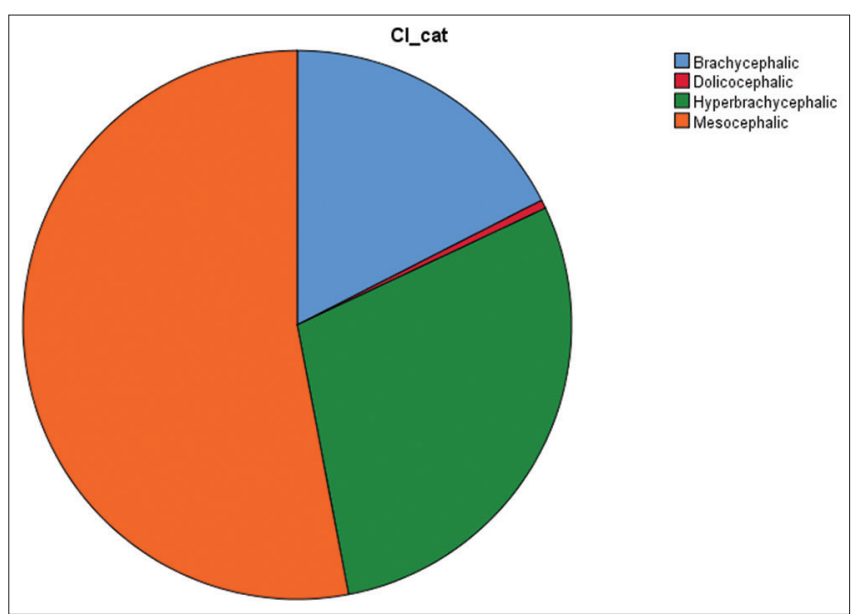

Figure 1: Classification of participants based on the cephalic index $(\mathrm{N}=200)$

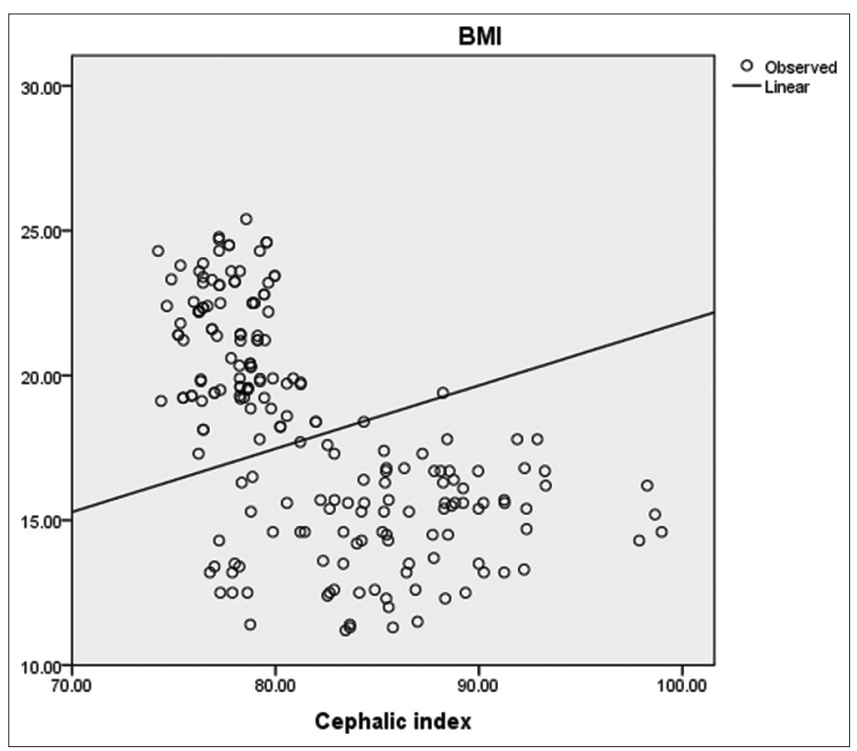

Figure 2: Correlation analysis of BMI vs. $\mathrm{Cl}$

Table 1: Comparison of cephalic index between male and female participants ( $n$ male $=100, n$ female $=100$ )

\begin{tabular}{lcc}
\hline Sex & Mean Cephalic index $($ mean \pm SD) & P-value \\
\hline Male & $82.05 \pm 5.9$ & 0.548 \\
Female & $81.59 \pm 4.9$ & \\
\hline
\end{tabular}

\section{DISCUSSION}

Our study aimed to assess the association between cephalic index and BMI in 5-8 years children in a rural municipality of Sarlahi district, Nepal. Our study found that the mean cephalic index in males and females are $82.05 \pm 5.9 \mathrm{~mm}$ and $81.59 \pm 4.9 \mathrm{~mm}$ respectively. While computing the CI of the subjects of the normal BMI, the mean CI of males was 77.65 and the mean BMI as 21.42 and that of the females, mean CI was 78.17 and the mean BMI as 21.18 which is in accordance with the study done by Esomonu and Badamasi et.al., ${ }^{8}$ where they stated that there was statistically significant difference in the cephalic index of male and female. In the present study it was observed that the majority head type among the children was mesocephalic.

On the other hand, it was observed that the majority of the subjects showed the mesocephalic type of skull in children with normal BMI. This is in accordance with the study done by Emma Rachmawati et al., according to them the most prevalence type of skull among the low BMI subjects were hyperbrachcephalic type which did not altered the thinking capacity of the subjects. ' Several study conducted on cephalic index in correlation with the BMI on other parts of the world had revealed that the cephalic index of the subjects slightly varies with the BMI without altering the intellectual capacity of an individual. A study done among adults in Gurung community of Nepal also showed the maximum of brachycephalic head type in their population (mean $\mathrm{CI}=84.6 \pm 5.14) \cdot{ }^{10} \mathrm{~A}$ study done by Pandey et. al. among the adults showed that dolichocephalic was predominant in her study done in Nepalese females $(\mathrm{CI}=78.36){ }^{11}$

As the present study is done in the children of Madheshi community, the $\mathrm{CI}$ may be altered in the adult age in other ethnicity of Nepal. Several researchers were interested in comparing several anthropological factors with intelligence where as some were comparing the data of newer generations with older generations and also some were comparing the indices in different groups and ethnicity in similar country. In this study, we particularly focused on the correlation of BMI and CI. Our findings demonstrate that the BMI influences the growth of size of the skull and $\mathrm{CI}$ as well.

Table 2: Types of head shapes in children (categorized by sex)

\begin{tabular}{|c|c|c|c|c|c|}
\hline Gender & Body Mass Index (BMI) & Cephalic Index (CI) & No. of participants(N) & $\%$ of participants & Types of Head \\
\hline Male & 14.85 (low BMI) & 86.50 & $50(33)$ & $66 \%$ & Hyperbrachycephalic \\
\hline Female & 14.87 (low BMI) & 85.01 & $50(27)$ & $54 \%$ & Hyperbrachycephalic \\
\hline Male & 21.42 (normal BMI) & 77.65 & $50(45)$ & $90 \%$ & Mesocephalic \\
\hline Female & 21.18 (normal BMI) & 78.17 & $50(45)$ & $90 \%$ & Mesocephalic \\
\hline
\end{tabular}




\section{CONCLUSION}

Our findings show that the common pattern of cephalic index was hyperbrachycephalic in the subjects of low BMI whereas the pattern of cephalic index in case of the normal BMI was mesocephalic type in both the male and female subjects. It confirms that the sexual dimorphism exists in case of the low BMI and normal BMI. It also concludes that the growth of the skull and crania are influenced by the body mass index. A large scale study is needed to confirm the relationship including diverse ethnic groups of Nepal.

\section{ACKNOWLEDGEMENT}

First of all the authors would like to thank the local government body of Ramnagar-7 Gaupalika, Sarlahi, Nepal for allowing us to carry out the study. Special thanks go to Mr. Radhe Shyam Sah for assisting in data collection and the respondents for co-operating in data collection. I would also like to thank Nobel Medical College for providing platform to conduct the study.

\section{REFERENCES}

1. Akinbami BO. Measurement of Cephalic Indices in Older Children and Adolescents of a Nigerian Population. BioMed Research International. 2014; 1-5.

https://doi.org/10.1155/2014/527473
2. Shah GV and Jadhav HR. The Study of Cephalic index in Students of Gujarat. J Anat Soc India. 2004; 53 (1): 25-26.

3. Williams PL, Bannister LH, Dyson M, Collin, Dussek JE and Ferguson JWM. Gray's Anatomy, 38 th Edn, Chur-chill Livingstone, Edinburgh, London 1995:609-12.

4. WHO Mean Body Mass Index (BMI)". World Health Organization. Retrieved 5 February2019.

5. Thakur R and Gautam RK. Cephalic growth pattern and nutritional status after 5 years of age: a cross sectional study among girls and boys of a central indian city-sagar (mp). Ind J Phys Anthrop \& Hum Genet. 2015; 34(1):39-46.

6. Ma NS and Gordon CM. Pediatric osteoporosis: where are we now? J Pediatr. 2012; 161:983-990. https://doi.org/10.1016/j.jpeds.2012.07.057

7. Patel N, Gunjana G, Patel S, Thanvi R, Sathvara P and Joshi R. Nutrition and health status of school children in urban area of Ahmedabad, India: Comparison with Indian Council of Medical Research and body mass index standards. J Nat SciBiol Med. 2015. 6(2):372-377.

https://doi.org/10.4103/0976-9668.160010

8. Esomonu UG and Bdamasi MI. Cephalic Anthropometry of Ndi Igba of Abia State of Nigeria. Asian J Sci Res. 2012; 5(3):178-184. https://doi.org/10.3923/ajsr.2012.178.184

9. Rachmawati E, Primarti RS, Zenab Y and Latif DS. Cephalic Index among Children of $6-8$ Year of Age with Low Body Mass Index in Bandung City, Indonesia. International Journal of Medical Science and Clinical Invention. 2019; 6(1): 4272-4274.

10. Lobo SW, Chandrasekhar TS and Kumar S. Cephalic index of Gurung community of Nepal- An anthrpometric study. KUMJ. 2005;3 (11):263-265.

11. Pandey N, Jha CB, Yadav G, Sah SK, Yadav P and Awasthi J. Study of Cephalic Index in Nepalese medical students. Int J Anat Res. 2016; 4(4): 3253-3256.

https://doi.org/10.16965/ijar.2016.453

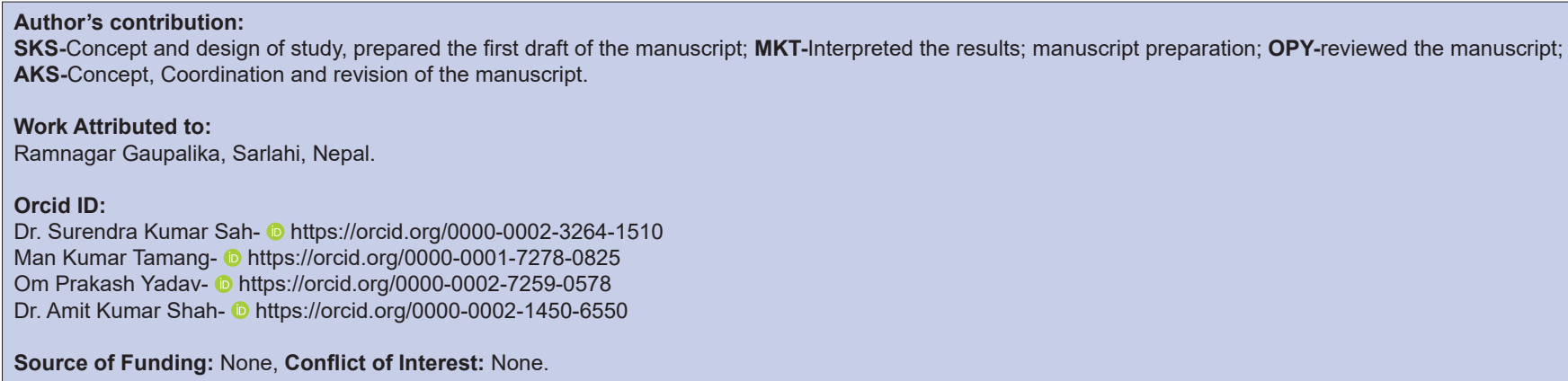

